\title{
THE PATTERN OF DISEASE IN SOUTH INDIAN CHILDREN
}

\author{
J. K. G. WebB, M.A., B.M., B.CH., M.R.C.P. \\ Professor of Padiatrics, Christian Medical College Hospital, Vellore, India
}

According to some estimates, the present population of India exceeds 400 million. Infants and children under 14 years of age form $38 \%$ of this total, and $50 \%$ of all deaths occur in this age group. The most recently published figure for the infant mortality rate is 108 (Ministry of Health Report, 1954-56). The provision of child health services to meet this huge need is still at a relatively early stage of development.

Although pædiatricians began working in a few centres some 30 years ago, it is only during the last ro years that medical schools have begun to realize the importance of this branch of medicine. A majority now have separate departments in the charge of a whole-time pædiatrician, but most of these are still woefully understaffed. As a result, the pædiatrician is apt to find all his resources of time and energy exhausted in the immediate care of an endless stream of sick children, and in essential teaching. Moreover, he usually needs to augment an inadequate salary by private practice. However, postgraduate courses have been started and interest in this field grows. With more generous staffing, and improved laboratory facilities, opportunities for the systematic study of disease are increasing.

To the western-trained pædiatrician, and this includes many Indians returning from postgraduate training in Britain or America, the pattern of disease in Indian children is quite unfamiliar. Some of the diseases are new to him; some familiar diseases are disguised by concomitant malnutrition or anæmia or by the advanced stage of the process when first seen. This pattern is only now being accurately described, and the picture is still far from complete. And yet, an accurate knowledge of this general pattern is an essential foundation to effective medical practice, and still more to effective teaching.

In this review, an attempt has been made to indicate this pattern as it is unfolding in South India. The viewpoint is consciously personal, in that almost all the data cited have been collected at the Christian Medical College Hospital, Vellore
(C.M.C.H.). Outpatient morbidity data would be reasonably representative of disease in the community, but are unfortunately not readily available. Inpatient data, though not representative, have been cited in the text as unqualified figures following the disease under discussion. These figures are the average annual admissions for the five years 1955-59, the average total annual admissions to the children's ward in the period being 905 . The newborn are not included in this total, the average annual deliveries at C.M.C.H. during the same five years being 1,654 .

\section{Newborn}

The vast majority of deliveries in India as a whole take place in the home. Of these only a small, though growing, percentage are attended by trained midwives. Accurate data in neonates are confined to the very small and better-cared-for group of infants born in hospital.

\section{Prematurity}

The average birth-weight in a representative population is lower than in the West. The mean for $I, 37 \mathrm{I}$ infants born at C.M.C.H. in 1959 was $5 \mathrm{lb}$. $14 \mathrm{Oz}$. with a distribution as shown (Fig. I): 442 weighed less than $5 \frac{1}{2} \mathrm{lb}$., i.e. about one third. Since it is ordinarily quite impossible to date conception, the period of gestation is rarely known accurately, and a correlation between this and birth-weight has never been attempted. All pædiatricians seem agreed that $5 \frac{1}{2} \mathrm{lb}$. as a criterion of prematurity is too high for Indian infants, $4 \mathrm{lb}$. $12 \mathrm{oz}$. being considered a more useful point of distinction. Further studies are required to verify the correctness of this view.

Mortality among small prematures born in hospital is high (Table $I$ ) and it is undoubtedly much higher among those born at home. No home follow-up on prematures born in hospital has been made, but it would certainly reveal a significant mortality during the first months after discharge. The prognosis for infants not wholly breast-fed at the time of discharge must be par- 


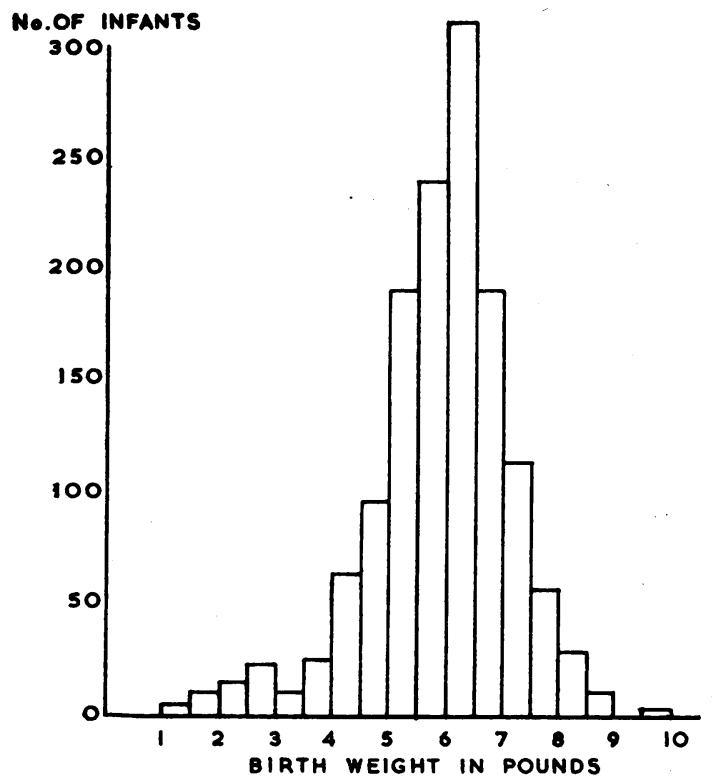

FIG. 1.-Distribution of birth-weight in $8 \mathrm{oz}$. groups of 1,371 infants born in C.M.C.H. in 1959.

ticularly bad in poor families who cannot long afford the infant's full requirement of cow's milk (I pt. of milk daily costs about one quarter of a poor family's total average income).

TABLE I

Mortality in Prematures, C.M.C.H. Vellore, 1959

\begin{tabular}{c|c|c|c}
\hline $\begin{array}{c}\text { Birth Weight } \\
\text { in Kg. }\end{array}$ & $\begin{array}{c}\text { Total } \\
\text { Births }\end{array}$ & Deaths & $\begin{array}{c}\% \\
\text { Survival }\end{array}$ \\
\cline { 1 - 1 }$<$ & 17 & 17 & - \\
\cline { 1 - 1 } 1.0 & 42 & 32 & 23.8 \\
$1.0-1.49$ & 73 & 22 & 69.9 \\
$1.5^{-1.99}$ & 310 & 15 & 95.2 \\
\hline
\end{tabular}

The view is widely held in India that hyaline membrane syndrome is very rare. Recent evidence suggests this view may be wrong. Autopsies were performed in 47 of the 86 prematures dying in C.M.C.H. in 1959. In four of these there was definite hyaline membrane, and in a further five marked pulmonary congestion with atelectasis.

\section{Birth Injury}

Although no detailed study of the incidence of birth injury has been made it is certainly an important cause of neonatal morbidity and mortality. Among the 47 prematures autopsied in 1959, there were seven (15\%) with intracranial hæmorrhage, and in a study of necropsy material from 215 stillbirths and neonatal deaths (latter defined as first three months of life) at C.M.C.H. between I95I and 1955 (Hadley,
Gault and Graham, 1958), 22 had intracranialo hæmorrhage.

\section{Congenital Abnormalities}

These again are a significant but largely un-c studied cause of neonatal mortality. Five among the 47 prematures autopsied in 1959 , and 31 in the series of 215 autopsies had gross congenital anomalies as the primary cause of death.

\section{Infection}

Infections are a major problem, both in the $e_{\infty}^{0}$ nurseries and in infants nursed beside their mothers. Thrush is common, the usual organism. being Candida tropicalis. Superficial staphylococ- $\vec{\omega}$ cal infections can be very troublesome, especially during the hot season. Penicillin-resistance iso the rule, $80 \%$ of staphylococcal strains isolated at 3 . C.M.C.H. in 1955 being resistant (Myers and ${ }_{y}^{\omega}$ Kamawa, 1956).

Respiratory infections are common. Pneumoniaur was found in six of the 47 prematures autopsied in $\vec{f}$ 1959. In the study of 215 autopsies, there were four stillbirths with well-developed pneumonia, $\rightarrow$ and pneumonia was the primary lesion in $4 \mathrm{I}$ of ${ }_{3}^{-}$ the neonatal deaths. In the whole series there were $2 \mathrm{I}$ where the pneumonia was consideredô to have begun in utero: 16 infants showed $a \vec{a}$ necrotizing pneumonia, without frank suppung-\% tion; bacteriological studies were not made, buta.coliform infection was suspected in some of thest.

Diarrhœa (89: $5.5 \%)$ is common, the majority of cases being infective gastro-enteritis. This has most frequently been due to one of the pathogenico serotypes of Escherichia coli. During an in- $\stackrel{\mathbb{Q}}{\varrho}$ vestigation of neonatal diarrhœa continued through $\vec{F}$ a 12-month period in $195^{8}$ (Prabhu), rectal3 swabs from 394 infants gave positive cultures in $71 ?$ cases. These included 42 of 105 infants with? diarrhœa, and 29 of 289 asymptomatic contacts. The strains isolated were $0_{55}: \mathrm{B}_{5}(62)$, o86 : $\mathrm{B}_{7} \stackrel{3}{\text { ב. }}$. (8), and or27 : B8 (I). During the same period, cultures from the I05 diarrhœal cases were all. negative for shigella and salmonella. However,o을 occasional cases of shigellosis are encountered; these are usually found to have been infected의 direct from their mothers.

\section{Hamolytic Disease}

The incidence of the Rh-negative blood group varies in different races in India; it is $12.5 \%$ among Parsis (Khanolkar, 1955), 5.3\% amongw Bengalees (Roy, Ghosh, Ray and Mitra, 1959), but is only $2 \%$ among blood donors in the localo Vellore population. Hæmolytic disease of the newborn due to $\mathrm{Rh}$-incompatibility might there-fore be expected in this region once in every $\mathrm{I}, 500$ deliveries. In the past three years, eight 


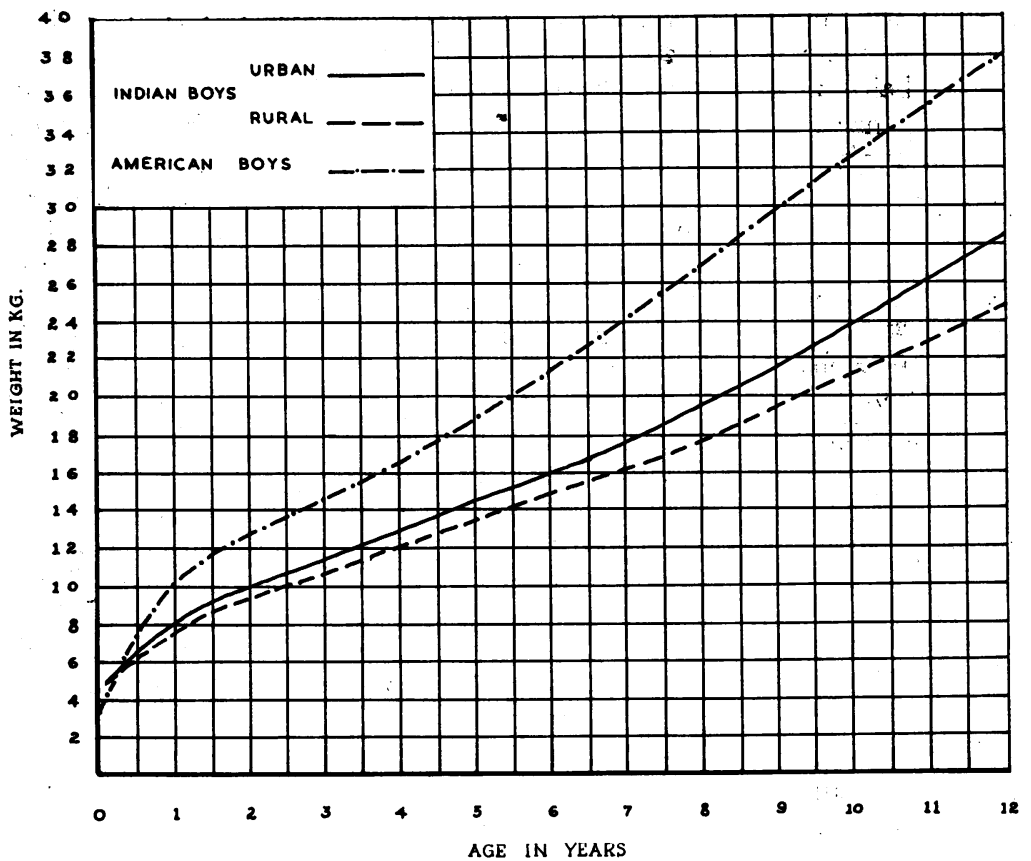

Fig. 2.-Weight curves for Indian and American boys. The Indian data are derived from the Annual Report, 1958-59, of the Indian Council of Medical Research, Nutrition Research Laboratories: the American data are the 5 oth percentile cited in 'Nelson's Textbook of Pediatrics', $7^{\text {th }}$ edition published by Saunders.

cases have been seen in some 4,500 deliveries; seven of these required exchange-transfusion, and there were two deaths. Where lack of an Rhnegative donor has necessitated the use of $\mathrm{Rh}$-positive blood, the results have still been satisfactory. During the same three-year period nine cases of $\mathrm{ABO}$ hæmolytic disease have been encountered, nine A-O, and one B-O. Seven of these were severe enough to require exchangetransfusion with maximum serum bilirubin levels ranging from $23.6 \mathrm{mg}$. $/ 100 \mathrm{ml}$. (at 24 hours) to $37 \mathrm{mg} . / 100 \mathrm{ml}$.

\section{Malnutrition}

A number of surveys conducted by certain national agencies and by the C.M.C.H. during the last five years have revealed very clearly the state of nutrition of rural and urban children in South India. Some degree of undernutrition is almost universal; gross malnutrition is extremely common.

Growth studies have shown that healthy children, as judged by clinical examination and health record, are markedly smaller and lighter than Western children (Fig. 2). Genetic factors may in part determine this small stature, but the consistently better physique of urban compared with rural children,* the improved physique

\footnotetext{
*Local convention defines 'rural' as resident in villages with a population of less than 5,000 , and ' urban' in cities with a population of more than 100,000 .
}

observed in experimental groups given supplementary protein feeds, the splendid early growth curve of infants receiving adequate breast-milk compared with the poor growth maintained in the postweaning period, and the distinct impression of superior stature among children of the well-to-do all point to the fundamental importance of nutritional causes. Moreover, careful dietary surveys have revealed a generally inadequate intake of both protein and calories, especially in the age-group six months to three years.

\section{Protein Malnutrition}

An immediate indication of the magnitude of this problem is the high incidence of kwashiorkor (85) among hospital admissions. These figures grossly understate the facts as only the severer cases can ordinarily be admitted, many children with frank nutritional œdema having to be treated as outpatients. Moreover, a South Indian Nutrition Survey (Someswara, Swaminathan, Swarup and Patwardhan, 1959) revealed that even florid cases of kwashiorkor may not be brought to hospital, an incidence of $1 \%$ being found among children under five years of age examined in the home.

In hospital cases, the typical features of kwashiorkor, weakness, apathy, growth retardation, wasting, œdema, hypochromo-trichosis and characteristic dermatoses are usually marked; xerophthalmia or keratomalacia, and less fre- 
quently angular stomatitis are common accompaniments. The extremely low serum-protein levels found in these cases are shown in Table 2. In the same table is shown the striking response to orthodox therapy with dried skimmed milk given for periods varying from two to four weeks.

TABLE 2

Serum-Protein Values in Eight Typical Cases of KWAShiorkor Before and After Treatment

(total protein estimated by biuret method, and fractions by paper electrophoresis (Dumm and Almas))

\begin{tabular}{|c|c|c|c|c|c|}
\hline \multirow{2}{*}{\multicolumn{2}{|c|}{$\begin{array}{l}\text { Serum Protein } \\
\text { (values in } \mathrm{g} . \% \text { ) }\end{array}$}} & \multicolumn{2}{|c|}{ Before Treatment } & \multicolumn{2}{|c|}{ After Treatment } \\
\hline & & \multirow{2}{*}{$\frac{\text { Mean }}{3.97}$} & \multirow{2}{*}{$\frac{\text { Range }}{3.10-6.80}$} & \multirow{2}{*}{$\frac{\text { Mean }}{6.64}$} & \multirow{2}{*}{$\frac{\text { Range }}{6.3-7.0}$} \\
\hline & & & & & \\
\hline Albumin & & & $-0^{2}-x$ & & $2+$ \\
\hline \multicolumn{6}{|l|}{ Globulin: } \\
\hline Alpha I & & 0. & 0.17 & 0.42 & $0.17-0$. \\
\hline & 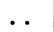 & & $0.38-1$ & 0.88 & $0.7 \mathrm{I}-$ \\
\hline & $\cdots$ & o. & 0.36 & 0.95 & $0.76-1$ \\
\hline ma & $\ldots$ & I.4I & $0.91-2.57$ & 1.12 & $1.50-1.97$ \\
\hline
\end{tabular}

A group of cases which prove extremely difficult to treat are those with hypoproteinæmia, the œdema often being masked by a diarrhœa sufficiently severe and persistent to cause some degree of dehydration. These cases cannot tolerate adequate protein feeds by mouth, and whole blood transfusion, or infusion of the dilute plasma obtained from time-expired donor blood rarely corrects the gross protein deficiency fast enough. Concentrated plasma or albumin might help but is not generally available, and is in any case prohibitively expensive.

\section{Avitaminoses}

Vitamin A. Some degree of vitamin A deficiency is extremely common. In a survey of village families (Rao, Klontz, Benjamin, Rao, Almas and Dumm, 1960) $23 \%$ of 200 children had xerosis and $18.7 \%$ pigmentation of the conjunctiva, and $6.9 \%$ had Bitot's spots. Serum vitamin A levels in the adult members of these children's families were extremely low, $12.5 \%$ having levels below $10 \mu \mathrm{g} / 100 \mathrm{ml}$., $54.8 \%$ below $20 \mu \mathrm{g}$./100 ml., and $86.9 \%$ below $30 \mu \mathrm{gg} . / 100 \mathrm{ml}$., which is generally regarded as the lowest adequate level.

The general incidence of keratomalacia is extremely high, being almost certainly the commonest cause of blindness. One has to be constantly alert for the earliest sign, faint haziness of the cornea, in all acutely ill children.

Vitamin $B$ Complex. Although deficiency of thiamine and nicotinic acid is reported from some parts of India, no child with beri-beri or pellagra has been seen in seven years at C.M.C.H. Riboflavin deficiency, however, is extremely common. Cheilosis was found in $5.3 \%$ of the village survey children, and angular stomatitis, active or healed, in $22.6 \%$ (Rao et al., 1960).

Significant vitamin $\mathrm{B}_{12}$ deficiency is evidently not common, but a small group of cases has been $\propto$ studied carefully at C.M.C.H. during the past two years (Baker, Jadhav and Webb). These children $\overrightarrow{\vec{F}}$ have fallen into two broad groups, those with other $-\overrightarrow{0}$ gross evidence of malnutrition such as kwashiorkor $\frac{\mathrm{C}}{\mathrm{O}}$ or marasmus, and an interesting group of breast- $\overline{\frac{\bar{\rho}}{5}}$. fed infants whose general nutrition has been good. $\bar{\nabla}$ Both groups have shown moderate anæmia and $a$ megaloblastic marrow. Some of the malnourished ${ }^{\infty}$ and all of the breast-fed infants have had more or $\vec{O}$ less marked changes in skin pigmentation; the $\vec{\overrightarrow{ }}$ affected areas, primarily the dorsa of the hands and ${ }_{\sigma}^{\omega}$ feet, but in some cases the full extent of the limbs, have shown a dark almost black coloration, 3 contrasting sharply with the lighter brown colour of the unaffected parts. Some of the breast-fed. infants have also shown neurological changes, a progressive apathy and unresponsiveness and $a \rightarrow$ very striking coarse, irregular tremor. This com- $\overrightarrow{0}$ bination of moderate anæmia, pigmentation and을 these neurological signs constitutes a clinical picture diagnostic of $\mathrm{B}_{12}$ deficiency in breast-fed $\overrightarrow{3}$ infants. The diagnosis has been confirmed in most of these cases by demonstrating low-serum $\supset$ $\mathrm{B}_{12}$ levels, and observing a therapeutic response $B_{12}$ given as the only addition to the previous dies, in some cases only in small dosage by mouth. Fi the breast-fed group, the $\mathrm{B}_{12}$ content of the mothers' breast-milk has been low, due apparently to a low dietary intake of $B_{12}$ or, in one instance, to an absorption defect for $\mathrm{B}_{12}$ in the mother.

Ascorbic Acid. Although dietary surveys indi- $\stackrel{2}{\rightleftharpoons}$ cate that a very low intake of ascorbic acid is $\frac{}{3}$ usual, infantile scurvy ( $I$ ) is very uncommon.

Vitamin D. Vitamin-D-deficient rickets is seen more frequently, perhaps a dozen cases a year. This incidence is low compared to that seen in 3 cities like Bombay or Calcutta. This may be due to the relatively greater exposure to sunlight of 3 . ' rural ' children. Vitamin-D-deficient rickets has to be distinguished from vitamin-D-resistant $₹$

rickets which is also seen.
Iron. Some degree of iron deficiency is extremely common. In the village survey $34.6 \%$ 음 of the children had a hæmoglobin of less than ro g. \%. In surveys of schoolchildren, the level in or rural children was lower than in urban (Table 3 ). N

Iron deficiency is by far the commonest cause $\underset{\mathrm{N}}{\mathrm{N}}$ of severe anæmia. Although ankylostomiasis and possibly loss of iron in sweat may contribute to this iron deficiency, the most important cause is $\frac{0}{\mathbb{D}}$ unquestionably a deficient intake of iron. The $\stackrel{\oplus}{+}$ age-group predominantly affected is six months to 0 four years, $84 \%$ of 140 cases studied falling within 0 this group (Jadhav and Baker). The very late 
TABLE 3

\begin{tabular}{|c|c|c|c|c|c|c|}
\hline & & & \multicolumn{2}{|c|}{ Boys } & \multicolumn{2}{|c|}{ Girls } \\
\hline & & & Rural & Urban & Rural & Urban \\
\hline $\begin{array}{l}\text { Hb. < } 10.0 \text { g. } \% \\
\text { Serum iron, } \mu \mathrm{g} . / 100 \mathrm{ml} .\end{array}$ & $\begin{array}{l}\cdots \\
\cdots\end{array}$ & $\begin{array}{l}\cdots \\
\cdots\end{array}$ & $\begin{array}{c}39.9 \% \\
95.6 \pm 2.53 \\
\end{array}$ & $\begin{array}{c}12.2 \% \\
105.67 \pm 2.21 \\
\end{array}$ & $\begin{array}{c}41.4 \% \\
93.15 \pm 3.24 \\
\end{array}$ & $\begin{array}{c}14.2 \% \\
116.18 \pm 4.49\end{array}$ \\
\hline
\end{tabular}

introduction of iron-containing foods into the average child's diet accounts for the extremely low hæmoglobin levels which may be seen even in children otherwise well nourished. The response of the anæmia to oral iron is usually excellent, and to intramuscular iron-dextran (until this preparation was withdrawn) dramatic.

\section{Digestive System}

\section{Gastro-Intestinal Tract}

Diarrhœa is unquestionably the commonest presenting symptom in pædiatric outpatients, and the commonest single cause of illness sufficiently severe to warrant admission to hospital. Some form of entero-colitis (157), bacillary dysentery (40.5) and amœbic dysentery (10) account for about $22 \%$ of all admissions. In addition, a very large number of cases are treated daily as outpatients.

In a bacteriological study of stools and rectal swabs from 853 unselected cases of diarrhœa (aged one month to 12 years) I24 (14.5\%) were positive for shigella and five for salmonella (Prabhu). At the time of this investigation, no attempt was being made to identify pathogenic serotypes of $E$. coli. These have since been isolated from a number of infants and young children and it is probable that they accounted for some of the $85 \%$ of cases in whom no fæcal pathogen was identified.

The ward cases range through the full clinical spectrum from acute dehydration in the basically well-nourished infant to chronic diarrhœa in the marasmic kwashiorkor. Their care constitutes a continuous salvage operation, with calls for an urgent intravenous drip, a regular source of interruption of residents' ward-rounds, seminars, or sleep. Orthodox therapy is adequate for most cases, provided circulatory failure has not developed. Sulphonamides alone (e.g., sulphadimidine g. $0.1 / \mathrm{lb} . / 24 \mathrm{hrs}$.) may not control all bacillary dysenteries, chloramphenicol and streptomycin being valuable though more expensive alternatives. The most troublesome group of cases, as mentioned already in the discussion of malnutrition, are those with chronic malnutrition and diarrhœa combined. In these, a further period of underfeeding only aggravates their critical debility; suspensions of pectin, pounded carrot, well-mashed plantain and thin rice porridge
(' congee') have proved helpful in checking diarrhœa, and thus permitting an earlier build-up of oral feeds.

Peptic Ulcer is evidently not uncommon. A series of $3^{6}$ verified cases of duodenal ulcer in children aged from 8 to 15 years has recently been reviewed (Ganguli, Ahmed, Narielvala, Bhat and Benjamin): I 7 of these presented with pain related to meals, 15 with pyloric stenosis, two with perforation and two with massive hæmatemesis. Gastroenterostomy was performed in 19 cases, and two of these developed anastomotic ulcers treated later with partial gastrectomy.

The extremely low incidence of acute appendicitis (4.5) and intussusception (2) is in striking and intriguing contrast to Western experience. The incidence of hypertrophic pyloric stenosis $(3.5)$ is also low.

\section{Liver Disease}

Liver disease achieves a prominence quite unknown in Western children. Infectious hepatitis (8) presents a familiar picture in older children, cases occurring sporadically and in periodic epidemics. However, during a recent epidemic in Vellore, five older children died with acute hepatic necrosis in a period of six months, which perhaps suggests undue severity.

The quite unfamiliar entity is a most sinister form of hepatic cirrhosis (23) of unknown ætiology, occurring in very young children, and commonly progressing to a fatal termination. This disease characteristically begins insidiously early in the second year with vague malaise, anorexia, weight loss and apathy as the presenting symptoms. There is usually no fever, and no jaundice initially, but the liver is markedly enlarged, firm, smooth or finely granular and not tender, and the spleen enlarges early. Biopsy and autopsy material reveal continuing hepatitis, with evidence of liver-cell necrosis and regeneration. Fibrous tissue containing proliferating bile-ducts encloses small islands of liver cells, giving rise to a picture of fine pseudo-lobulation. The disease tends to progress relentlessly but with varying rapidity. In some cases the total duration up to death from hepatic failure, usually with jaundice and ascites developing terminally, is only three to four months. In others, the course is measured in years; in these, a more extreme form of nodular cirrhosis with portal 
hypertension develops, when death may be due to hæmorrhage from æesophageal varices. Just occasionally the hepatitis becomes arrested, or resolves completely. In a few instances, serial biopsies have revealed complete disappearance of established pseudo-lobulation.

This childhood hepatic cirrhosis is most often seen in middle-class families, and very rarely in the poorest section of the population where kwashiorkor is common. A number of follow-up studies of kwashiorkor have failed to demonstrate progressive hepatic cirrhosis. Although nutritional factors may contribute, it therefore seems clear that malnutrition alone cannot be responsible. The histological changes are different from those seen in the veno-occlusive disease of Jamaica, and, with its relatively late onset, it appears to be distinct from neonatal hepatitis, examples of which have been encountered. An infective atiology seems most probable and support for this has been provided by Achar. He has studied serial liver biopsies from children presenting the typical picture of childhood cirrhosis, from children with 'infectious hepatitis' (i.e., an illness with a more abrupt onset with early jaundice and presumed due to the virus of infectious hepatitis) and from the siblings of both groups who had palpable livers, but were not otherwise ill. He has demonstrated similar pathological changes in livers from each of these four groups of children. On the supposition of an infective ætiology, he has treated cases with regular injections of gamma-globulin, apparently with some measure of success.

Hæmatogenous staphylococcal abscess (four cases seen), hydatid diseaee (two cases seen), the granulomatous infiltration peculiar to tropical eosinophilia, the fatty liver of kwashiorkor and miliary tuberculosis, Gaucher's disease, neonatal ' giant-cell' hepatitis, syphilitic hepatitis and primary hepatoma are some of the other forms of liver disease encountered.

\section{Respiratory Tract}

Although Vellore's is a hot, dry climate, the incidence of acute upper respiratory infections, otitis media and follicular tonsillitis appears to be very much the same as in the temperate zones, with a slight seasonal increase noticeable during the monsoons. However, contrary to expectation, chronic upper respiratory infection and sinusitis are relatively uncommon.

Pneumonia (100) is responsible for more than $10 \%$ of all admissions, and these, of course, represent only a selection of the more severe cases, uncomplicated early pneumonia being treated ordinarily in outpatients. As with all infections, delay in bringing the child for treatment, undernutrition and anæmia contribute to a relatively high complication rate. It is not uncommon to find a lung abscess present within one to two weeks of the onset of illness. These early cases of lung abscess will often resolve with appropriate antibiotics and correction of malnutrition and anæmia, but many of the cases are more chronic, and require resection. Empyema (10) is also a relatively common condition.

The staphylococcal pneumonias of infancy and early childhood form a distinct group. A series of 23 bacteriologically proved cases (Jadhav and Gopinath) seen in a period of 30 months included examples of single tension cavities (I), multiple pneumatocoeles (3), tension pyopneumothoraces (5) and empyemata (18): $90 \%$ of these staphylococcal strains were penicillin-resistant.

Bronchiectasis (20) is frequently seen as a diffuse cystic change involving the whole of the lung which shows some degree of collapse consolidation. When this condition was first encountered, the findings suggested infection supervening on congenital cystic disease of the lung. However, the development of this cystic change has been observed in serial chest radiographs in a number of children, so it appears to be the result of infection. This type of cystic bronchiectasis is commoner than the basal bronchiectasis usual in the West. Surprisingly, even with grossly infected bronchiectasis, Indian children rarely have concurrent chronic sinusitis.

Asthma is in no way peculiar, except in so far as? it has to be differentiated all the time from tropical pulmonary eosinophilia. Hydatid cysts of the lung (five in five years) are a rarity.

\section{Cardio-vascular System Acute Rheumatism}

Acute rheumatism (35) is the commonest cause of acquired cardiac disease, and presents in a way now relatively unfamiliar in the West. Analysis of a consecutive series of 166 cases (Vaishnava, Webb and Joseph, 1960) under 13 years of age revealed a number of surprising features. Although $90 \%$ had polyarthralgia at some time, objective signs of arthritis were seen in only four cases. Subcutaneous nodules, though searched for consistently, were seen in only two cases. Of the 161 children with rheumatic heart disease, only 24 presented the picture of early carditis; in $137(82.5 \%)$, irreversible or almost certainly irreversible cardiac lesions were present at the time of admission. Seventy-five cases $(45 \%)$ were admitted with signs of congestive cardiac failure.

Mitral stenosis was present in 90 cases $(54 \%)$, the diagnosis being made in I I children aged less than nine years. Autopsy confirmation of mitral stenosis was obtained in six children aged $8,9,10$, 
I I, 12 and 12 years respectively. Mitral valvotomy was performed in four of the 90 cases, the ages of the children at the time of operation being nine years (2), I I years and 12 years. Growing experience confirms the need for operation in children even younger than this.

\section{Congenital Heart Disease}

The presence at the C.M.C.H. of the first thoracic surgical unit in India has drawn children with congenital heart disease from a very wide area. Table 4 shows an analysis of 383 cases studied during the five-year period I955-59 (Mazumdar and Vytilingam). Diagnosis was established by catheterization and angio-cardiography where necessary. The large miscellaneous group has not been further broken down because a completely certain diagnosis was not established, but this group included many cases of truncus arteriosus, pentalogy, and transposition of the great vessels. The group of 'other vascular malformations' included a variety of vascular anomalies.

\section{TABLE 4}

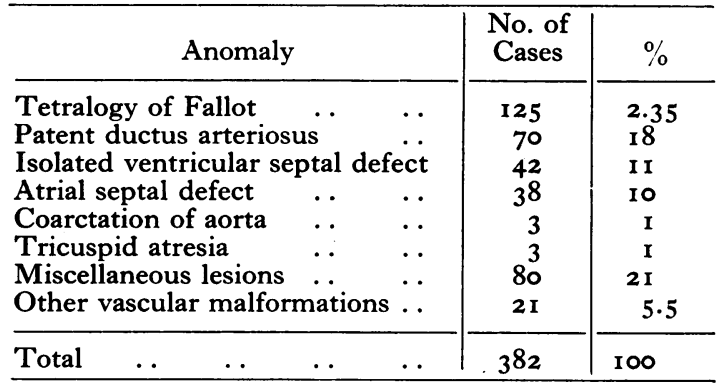

Apart from rheumatic carditis and congenital anomalies congestive cardiac failure is common as a result of severe anæmia, acute nephritis, and a combination of infection, malnutrition and anæmia. Where the anæmia is significant, exchange transfusion with packed cells has proved dramatically successful. In addition, a small group of children presents with chronic congestive cardiac failure, apparently due to none of these causes. In these, the heart is enlarged, gallop rhythm is often present, murmurs are inconspicuous, the electrocardiograph is variable, and the immediate response to digitalis has been good. Some form of myocarditis is evidently present, but autopsies have been too few to show whether this is a homogeneous group. One such case proved at autopsy to be endomyocardial fibrosis.

\section{Genito-urinary}

Acute Glomerulo-Nephritis (23) tends to present in a rather severe form. This is probably in part due to the fact that micturition in a drain or a field provides no opportunity for the early recognition of hæmaturia. Children are, therefore, seldom brought to hospital until gross œdema, or the dyspnœa of early congestive cardiac failure have developed. The precipitating streptococcal infection appears frequently to be an impetigo complicating scabies rather than a throat infection, but this has not been proved by bacteriological studies.

Nephrosis (13) is not in any respect unusual: the obvious alternative therapy with malaria for those cases unable to afford steroids has proved difficult to implement because of the rarity of malaria. Pyelonephritis (6) is surprisingly uncommon; it occurs almost invariably as a complication of some obstructive lesion in the renal tract and is practically never seen as a primary disease in infancy.

\section{Central Nervous System Mental Defect}

Primary mental defect with or without cerebral palsy is extremely common. Unfortunately, only a very small minority of cases is normally admitted, and accurate outpatient statistics are not readily available. No detailed investigation of this problem has been attempted, and generalizations are of doubtful value. However, it seems clear that, in addition to the possible effects of malnutrition and infections, genetic factors contribute to the high incidence. First-cousin marriages are frequent, and uncle-niece marriages not rare. Familial mental defect has been seen repeatedly, not only in siblings, but also through two generations, often in circumstances where hope for a normal heir has led a family to arrange the marriage of a defective male. Cerebral palsy due to birth injury or infections is common. The incidence of mongolism is probably very much the same as in the West.

\section{Infections}

Meningitis. Tuberculous meningitis (28) is a depressing disease to treat in India. Out of the last 58 cases, only $12(20 \%)$ seem likely to recover completely: $17(29 \%)$ dię in hospital, 16 $(27.5 \%)$ were discharged essentially unchanged, and in $13(22 \%)$ the disease was controlled but there were severe residua, optic atrophy, mental defect or pareses. Treatment of these cases has included the use of prednisolone, but no intrathecal medication. The bad results are largely due to the advanced stage of the disease at the time of admission to hospital. Only one of these $5^{8}$ cases was fully lucid at the time of starting treatment; the majority had already had fits, were deeply comatose and showing focal neurological signs.

Pyogenic meningitis (I I), with recovery in 33 ( $46 \%$ of a series of 72 cases), fares a little better. 
The organism was identified in 63 of the 72 cases (Table 5). Subdural loculations were found in

TABLE 5

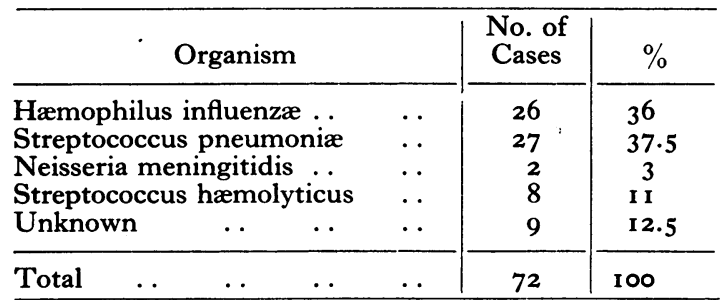

18 cases $(25 \%)$. This high incidence of subdural effusion and the relatively poor results in spite of full antibiotic therapy is again largely due to the late stage of the disease at the time of admission.

Encephalitis. Many children are seen with some form of encephalitis (3I). Since I955, a collaborative investigation of these cases with the Virus Research Centre, Poona (V.R.C.) (Webb and Pereira, 1956, 1957; Work and Shah, 1956), has confirmed that they are a heterogeneous group embracing Japanese B encephalitis, allergic encephalo-myelitis (post-vaccinal, etc.), encephalopathies associated with acute bacterial infections, and a large and doubtless still mixed group in which the cause cannot be determined.

Cases of Japanese B encephalitis have been seen at C.M.C.H. in four of the six years since 1955 when the diagnosis was first made. They always occur during the monsoon season from September to December. They are drawn from a wide area of South-East India, from scattered farms and villages, children aged 4 to 12 years being the age-group predominantly affected. The clinical picture, with a febrile prodromal stage of up to three days, and an encephalitic stage marked by coma, convulsions, choreo-athetoid movements, pareses, and continuous fever which may last for many weeks, is fairly characteristic. A polymorph leucocytosis and a pleocytosis in the cerebrospinal fluid are usual. About one third of the cases die during the acute stage of the illness, one third are left with residua, mental defect or pareses, and one third make a complete recovery. Serological support for the diagnosis has been obtained in some 40 cases. JBE virus has been isolated from the brains of three children, in two from tissue obtained through burr-holes made immediately after death, and in one from a brain biopsy taken during the acute encephalitic stage of the illness. This last child went on to make a complete recovery.

Acute encephalopathies due to bacterial infections, typhoid or pneumococcal septicæmia being examples, have on occasion presented clinical pictures indistinguishable from Japanese $B$ en- cephalitis, even to the pleocytosis in the C.S.F. All such cases are, therefore, routinely treated with tetracycline once blood has been taken for culture and virus studies.

The cases of allergic encephalomyelitis, a small group, can be recognized by the signs or history of the exanthem. The remaining cases form a disturbingly large group of unidentified encephalitides. It is almost certain that many of these are due to unidentified viruses, such as appear to have been responsible for the large epidemics reported in other parts of India. Some cases probably represent the result of vascular lesions developing in the course of an acute infection.

Parasitic Infections. Occasional cases of cysticercosis and hydatid disease of the brain or spinal cord have given rise to difficulty in diagnosis.

Intracranial Space-occupying Lesions. In I I years, 136 children presenting with intracranial space-occupying lesions have had this diagnosis verified by the C.M.C.H. Neurosurgical Unit (Chandy). Table 6 shows the diagnosis in these cases. The importance of tuberculoma is obvious.

\section{TABLE 6}

Verified INTRACRANial Space-occupying Lesions, C.M.C.H., 1949-60

\begin{tabular}{|c|c|c|c|c|c|}
\hline \multicolumn{4}{|c|}{ Diagnosis } & \multirow{2}{*}{$\begin{array}{c}\begin{array}{c}\text { No. of } \\
\text { Cases }\end{array} \\
39\end{array}$} & \multirow{2}{*}{$\frac{\%}{28.7}$} \\
\hline \multirow{4}{*}{\multicolumn{2}{|c|}{$\begin{array}{l}\text { Tuberculoma . } \\
\text { Medulloblastoma } \\
\text { Astrocytoma . } \\
\text { Craniopharyngioma }\end{array}$}} & $\cdots$ & . & & \\
\hline & & $\ldots$ & $\ldots$ & 20 & 14.7 \\
\hline & & . & $\ldots$ & 17 & 12.5 \\
\hline & & . & . & 8 & 6.0 \\
\hline Glioma $\cdots$ & . & . & . & 7 & 5.0 \\
\hline \multicolumn{3}{|c|}{ Third ventricle tumours } & . & 4 & 3.0 \\
\hline Ependymoma & . & . & . & 7 & 5.0 \\
\hline Angioma .. & . & $\cdots$ & $\cdots$ & 3 & 2.2 \\
\hline Meningioma & $\cdots$ & $\cdots$ & $\cdots$ & 3 & 2.2 \\
\hline Cysticercosis & $\cdots$ & $\cdots$ & $\cdots$ & 3 & 2.2 \\
\hline Hydatid cyst & $\cdots$ & $\cdots$ & $\cdots$ & 2 & I. 5 \\
\hline Miscellaneous & $\cdots$ & $\cdots$ & $\cdots$ & 23 & 17.0 \\
\hline Total & $\ldots$ & $\ldots$ & .. & 136 & 100.0 \\
\hline
\end{tabular}

As $75 \%$ of all intracranial tuberculomata were in the posterior fossa, tuberculoma is an appreciably commoner cause of the posterior fossa syndrome than medulloblastoma. Not infrequently genuine difficulty may be experienced in the differential diagnosis of posterior fossa tuberculoma and tuberculous meningitis. A policy of early surgical removal has been followed. In the first 26 cases so treated, there were 14 early deaths, and recovery is known to have been complete in six of the other 12.

\section{Blood}

Iron deficiency and megaloblastic anæmias have already been described. Rare but ințeresting 
anæmias encountered include thalassæmia major (six cases), congenital spherocytosis (one case), congenital ovalocytosis (one family) and the anæmia associated with osteopetrosis (3 cases) (Baker). Congenital syphilis and chronic amœbiasis have also presented on occasion as anæmia.

The commonest hæmorrhagic disorder encountered has been idiopathic thrombocytopenic purpura. A full investigation of 18 consecutive children with some defect of the clotting mechanism revealed hæmophilia in 10, Christmas disease in one, Stuart-Prower Factor deficiency in four, plasma thromboplastin antecedent deficiency in one, and vascular hæmophilia in two (Baker). Hæmorrhagic disease of the newborn is seen occasionally, and hæmorrhagic states associated with chronic liver disease are not uncommon.

\section{Infectious Diseases \\ Bacterial}

The various manifestations of hæmolytic streptococcal infection, follicular tonsillitis, otitis media, impetigo, cellulitis, and the allergic reactions, rheumatic fever and glomerulo-nephritis, are fully as common as in temperate zones.

Staphylococcal infections of the skin are extremely common, of the lung and pleura fairly common in infancy, and of bone and joint perhaps less common than might be expected. Diphtheria is seen regularly, and diphtheritic polyneuritis is not uncommon. Pertussis is usual in infants and pre-school children. Vincent's infection is common as an ulcerative gingivitis, less common as a stomatitis, and mercifully rare as cancrum oris.

Tuberculosis (103) is a major problem, meningitis (28), bone and joint disease (23) and pulmonary disease (24) accounting for most of the admissions. Typhoid (with both paratyphoid A and B) is endemic (45). Congenital syphilis (12) is seen regularly with all its diverse manifestations. Tetanus is seen in both the neonatal period (I.5) and in older children (5.5), and in these the absence of a demonstrable site of infection is both usual and puzzling. Leprosy is fairly common, entering urgently into the differential diagnosis of all hypopigmented skin lesions. Brucellosis is seen very occasionally. Bubonic plague has not been seen, but has not yet been completely eradicated from South India.

\section{Virus}

The common infectious diseases, measles, varicella and mumps are in no way unusual, and, judging by clinical signs, the various respiratory viruses are just as active as in a temperate climate. In spite of a rigorous programme of vaccination, small-pox is still endemic in Madras; a number of children have been seen with severe multiple osteitis as a complication of the disease. Rabies, though rarely seen, is a constant potential danger. Rickettsial infections are very rare possible causes of obscure fevers.

During the past five years, a joint study of the role of arbor viruses has been maintained with the V.R.C. In addition to the JBE virus, West Nile virus has been isolated from mosquitoes (Virus Research Centre, Poona). In 1959, during the season of maximal mosquito breeding (SeptemberDecember), a study of febrile children was made at C.M.C.H. to determine the importance of the arbor viruses as a cause of fever. The isolation of dengue virus from the blood of three children was the only immediate finding (Virus Research Centre, Poona), but the full picture will be seen only when serological studies on the 300 paired sera are complete. However, the present impression is that arbor viruses are not a numerically important cause of disease.

Entero-viruses have in general been less studied, but must be of the greatest importance. Poliomyelitis is endemic, though periodic epidemics have been reported in Bombay. Paralytic cases are seen at C.M.C.H. throughout the year, the disease being almost confined to children between the ages of six months and four years. Poliovirus has been isolated repeatedly from the stools of typical cases. Coxsackie $A$ virus has been isolated from the blood of a febrile child who showed the? clinical features of herpangina (Virus Research Centre, Poona). The role of Coxsackie and $\mathrm{ECHO}$ viruses in diarrhœas, aseptic meningitis, and the obscure encephalitides remains to be explored.

\section{Parasites}

Malaria (8), as a result of an extensive and sustained campaign, has ceased to be an important problem. By contrast, very little impression has been made on filariasis which is still widespread, in some localities hyper-endemic. Symptoms due to filariasis are very rarely seen in children, evidence of infection being virtually confined to the occasional demonstration of microfilariæ ( $W$. bancrofti) in the blood.

Tropical eosinophilia is, however, quite common in children. These cases usually present with cough, worse at night, and continuing with relatively little systemic disturbance for weeks or months. Many children have a significant lymphadenopathy and moderate hepatomegaly. Most cases show a characteristic hazy reticulation or mottling in lung radiographs, an absolute eosinophil count above 4,000 per $\mathrm{mm}^{3}{ }^{3}$, a positive filarial complement fixation test, and a good therapeutic response to diethylcarbamazine. Sections of lung, 
liver and lymph-nodes show an eosinophil granulomatous reaction in which microfilariæ have been demonstrated (Webb, Job and Gault, 1960). The disease thus appears to be due to a filarial infection, though the vector mosquito and the species of filaria concerned have yet to be identified.

Kala-azar is very rarely seen, being almost confined in Madras State to one suburb of Madras City.

Infection with intestinal parasites is extremely common. In a health survey of schoolchildren in Vellore and nearby villages (Rao et al.) 9$9.5 \%$ of the children were infected with roundworm, and $4.5 \%$ of the urban and $20.3 \%$ of the rural children with hookworm. The hookworm load is rarely sufficient in this area to be the main cause of anæmia. Children occasionally present with abdominal pain due to masses of roundworms which can be identified on palpation of the abdomen. Such cases will pass 50 to 100 worms after treatment with piperazine.

Pediculosis capitis and scabies are extremely common.

\section{Miscellaneous \\ Poisoning}

Accidental poisoning, though relatively uncommon, is seen occasionally, kerosene being the commonest offender. Although cobras, kraits and Russel vipers are to be found throughout the region, no case of snake-bite has presented in seven years.

Scorpion-sting, on the other hand, is not infrequent, and in infants and young children may be fatal. There is a deceptive interval of several hours between the sting and the onset of peripheral circulatory collapse, which in recent experience has failed to respond to intravenous plasma, noradrenaline and hydrocortisone. Although deaths due to this cause must be numerous, no anti-venom is available in India.

\section{Behaviour Problems .}

This is a huge subject involving a consideration of cultural patterns and quite beyond the scope of this review. In general it may be said that problems arise, or are recognized, only in middle- and upper-class families. The extreme permissiveness normally shown by a family towards the infant and young child, especially boys, is replaced at the time he starts school by a most demanding attitude. Minor disturbances of behaviour, often centring round feeding, are very common in young children, and a variety of hysterical symptoms not uncommon in older children. Aphonia, bizarre gait, paralysis, fits and retention of urine are among the hysterical symptoms which have been seen.

\section{Conclusion}

The attempt to paint a picture of disease in Indian children has been made. Much that might have been described has been omitted, but, even so, the effort to furnish detail has reduced parts of this review to a dull catalogue of facts. But the life of an Indian pædiatrician is anything but dull. The volume of disease and its severity are at times daunting. The problems are certainly gigantic. But acquiescence in the status quo is passing. A mounting enthusiasm to tackle the problems is everywhere evident, and to be involved in this great enterprise is an absorbing and exhilarating experience.

\section{Summary}

I. The pattern of disease in South Indian children, based mainly on experience at the Christian Medical College Hospital, Vellore, is reviewed.

2. Among topics discussed are diseases of the newborn, those due to malnutrition, diseases of the digestive system, respiratory tract, cardiovascular system, genito-urinary tract, central nervous system, blood, and infectious diseases.

\section{Acknowledgments}

Although references have been given wherever possible to indicate sources of data, much of the material used has been collected by colleagues too numerous to mention individually. It is a pleasure to acknowledge the extreme readiness with which they made their material available. I would also like to thank Dr. Malati Jadhav, lecturer in pædiatrics, for her very real help during the preparation of this article, and Mr. D. Gajaraj, record librarian, for his efficient assistance with records.

\section{REFERENCES}

Achar, S. T.: Personal communication.

BAKER, S. J.: Unpublished data.

, Malati Jadhav and WebB, J. K. G.: Megaloblastic Anæmia due to $\mathbf{B}_{\mathbf{1 2}}$ Deficiency in S. Indian Infants. To Chandy, J.; Unpublished data.

Dumi, M. E., and Almas Begum: Unpublished data.

Ganguli, P. C., Ahmed, I., Narielvala, F. M., Bhat, H. S., and Benjamin, V.: Personal communication.

HADLEY, G. G., GAulT, E. W., and GrahaM, M. D. (1958): A Study of Pathology of Stillbirths and Neonatal Deaths in South India, Y. Pediat., 3, 139.

KHANOLKAR, V. R. (1955): Genetic Variation in People of Western India, Indian Y. med. Sci., r99. 
Malati Jadhav and Baker, S. J.: Ætiology of Severe Anæmia in Fifty Children. In press.

and Gopinath, N.: Staphylococcal Pneumonia. In press.

Mazumdar, H., and Vytilingam, K. I.: Congenital Heart Disease in the Pediatric Age Group. In press.

Ministry of Health, NeW Delhi: Report for 1954-56.

Myers, R. M., and Kamawa Achaya (1956): Antibiotic Sensitivity Tests in Routine Diagnostic Bacteriology, Indian F. med. Sci., 8, 6 r 4 .

Prema Prabhu, G.: Studies on the Etiology of Diarrhœa in Children with particular reference to the Pathogenic Serotypes of Escherichia coli. Thesis for M.Sc., Madras University.

Rao, B. R. H., Klontz, C. E., Benjamin, V., Rao, P. S. S., Almas Begum and Dumm, M. E.: Nutrition and Health Status Survey of School Children-Rural School Children in Kaniyambadi Valley, N. Arcot. In press.

,,,,$-----(\mathrm{r} 960)$ : Nutrition Status Survey of the Rural Population in Sholavaram, $\mathcal{F}$. Indian med. Ass., 6, 259.

Roy, M. N., Ghosh, S., Ray Mahasaya, D., and Mitra, P. C. (r959): Incidence of Rh-Negative Rate and Nature of Phenotypes Amongst the Bengalees, Ibid., 32, ro.

Someswara Rao, K., Swaminathan, M. C., Swarup, S., and Patwardhan, V. N. (I959): Protein Malnutrition in South India, Bull. Wld Hlth Org., 20, 603.

Vaishnava, S., Webb, J. K. G., and Joseph C. (1960): Juvenile Rheumatism in S. India, Indian Y. Child Hlth, 9290.

Virus Research Centre, Poona: Unpublished data.

Webb, J. K. G., Job, C. K., and Gault, E. W. (1960): Tropical Eosinophilia. Demonstration of Microfilariæ in Lung, Liver, and Lymph-Nodes, Lancet, 835 .

- and Pereira, S. M. (1956): Clinical Diagnosis of an Arthropod Borne Type of Encephalitis in Children of North Arcot District, Madras State, India, Indian f. med. Sci., 8, 573.

- - (1957): Further Studies in Acute Encephalitis in Children in South India. Indian Y. Child Hlth., 6, 217.

Work, T. H., and SнAн, K. V. (1956): Serological Diagnosis of Japanese B type of Encephalitis in North Arcot District of Madras State, India, with Epidemiological Notes, Indian $\mathcal{F}$. of med. Sc., ro, 582. 